\title{
Kadın ve Erkeklerde Olumsuz Değerlendirilme Korkusunun Belirlenmesinde Algılanan Ebeveyn Tutumları ve Benlik Saygısının Rolü
}

\section{The Role of Self-Esteem and Perceived Parental Attitudes in Determining Fear of Negative Evaluation in Men and Women}

\author{
Sinem Cankardaş ${ }^{1}$ (i)
}

Bu çalışmanın bulguları 23 - 25 Ocak tarihleri arasında Porto/Portekiz'de gerçekleşen International Conference on Child and Adolescence 2019 'da sözel olarak sunulmustur. Yazar, Prof. Dr. Ömer Faruk Şimșek'e analiz konusunda verdiğ destekten ötürü teşekkür eder. / The findings published here were presented at International Conference on Child and Adolescence 2019, held in Porto/Portugal, 23 - 25 January. The author would like to thank Prof. Ömer Faruk Simsek for his support for the analyses.

'Dr. Öğr. Üyesi, İstanbul Arel Üniversitesi, Psikoloji Bölümü, İstanbul, Türkiye

ORCID: S.C. 0000-0003-4140-2068

Sorumlu yazar/Corresponding author: Sinem Cankardas,

İstanbul Arel Üniversitesi, Psikoloji Bölümü, İstanbul, Türkiye

E-posta/E-mail: sinemcankardas@arel.edu.tr

Başvuru/Submitted: 08.09.2018

Revizyon Talebi/Revision Requested:

23.10.2018

Son Revizyon/Last Revision Received:

08.04.2019

Kabul/Accepted: 10.04 .2019

Online Yayın/Published Online: 20.05.2019

Atıf/Citation: Cankardas, S. (2019). Kadın ve erkeklerde olumsuz değerlendirilme korkusunun belirlenmesinde algulanan ebeveyn tutumları ve benlik saygısının rolü. Psikoloji Çalışmaları - Studies in Psychology, 39(1): 79-97.

https://doi.org/10.26650/SP2018-0022
ÖZ

Alan yazındaki bulgular olumsuz değerlendirilme korkusunun beden dismorfik bozukluğu, yeme bozuklukları, sosyal kaygı gibi birçok bozuklukla ilişkili olduğuna işaret etmektedir. Bu nedenle olumsuz değerlendirilme korkusunun ortaya çıkışında etkili olan faktörlerin tespit edilmesi, ruh sağlığ1 alanında önleyici programlar geliştirmede oldukça önemlidir. Olumsuz değerlendirilme korkusunun düşük benlik saygısı ve reddedici ebeveyn tutumları ile ilişkili olduğuna dair çalışmalar bulunsa da bu konudaki bilgi yeterli değildir. Yapılan bu çalışmada hem kadın ve erkeklerin ebeveynlerinden farklı tutumlar gördüğü varsayımını test etmek hem de kadın ve erkeklerde olumsuz değerlendirilme korkusunun belirlenmesinde benlik saygısı ve algılanan ebeveyn tutumlarının rolünün araştırılması amaçlanmıştır. $\mathrm{Bu}$ amaçla 125'i kadın olmak üzere 230 üniversite öğrencisi Rosenberg Benlik Saygısı Ölçeği, Kısaltılmış Algılanan Ebeveyn Tutumları Ölçeği Çocuk Formu ve Olumsuz Değerlendirilme Korkusu Ölçeği Kısa Formu doldurmuştur. Yapılan bağımsız gruplar için $t$ testi sonucu ebeveynden algılanan duygusal sıcaklık ve reddedicilik puanlarının cinsiyete göre farklılaştığı görülmüştür. Buna göre kadınlar ebeveynlerinden daha fazla duygusal sicaklık görürken, erkekler daha fazla reddedici tutumlar deneyimlemektedir. Kadın ve erkeklerde olumsuz değerlendirilme korkusunu yordayan değişkenleri tespit edebilmek için iki ayrı regresyon analizi yapılmıștır. Kadınlarda düşük benlik saygısının olumsuz değerlendirilme korkusundaki varyansın \%12'sini açıkladığı ancak erkeklerde benlik saygısının olumsuz değerlendirilme korkusunu belirleyen bir değişken olmadığı görülmüştür. Bunun yerine erkeklerde ebeveynin aşırı koruyucu tutumunun olumsuz değerlendirilme korkusu üzerinde etkili bir değişken olduğu ve olumsuz değerlendirilme korkusu düzeyindeki varyansın \%20'sini açıladığ bulunmuştur. Elde edilen bulgular, hem olumsuz değerlendirilme korkusunun ortaya çıkışında etkili faktörlerin araştırılmasında hem de önleyici müdahaleler geliştirilmesinde toplumsal cinsiyet rolü beklentilerinin de göz önünde bulundurulması gerektiğine işaret etmektedir. Çalışmanın bulguları ışığında kadınlarda benlik saygısını geliştirmeye yönelik bireysel müdahalelerin, erkeklerde ise ebeveynleri hedef alan ve olumlu ebeveyn tutumlarını geliştirmeye yönelik eğitim programlarının etkili önleyici müdahaleler olabileceği düşünülmüştür.

Anahtar Kelimeler: Algılanan ebeveyn tutumları, olumsuz değerlendirilme korkusu, benlik saygisı, sosyal anksiyete, cinsiyet 


\section{ABSTRACT}

The findings in recent literature indicate that fear of negative evaluation is related to many disorders such as body dysmorphic disorder, eating disorders and social anxiety. Therefore, determining the factors that affect the development of fear of negative evaluation seems important for developing preventive programs in the field of mental health. Although previous studies reported that the fear of negative evaluation is related to low self-esteem and rejecting parental attitudes, our knowledge is still inadequate in this area. The aim of this study was to both test the assumption that the attitudes of parents of women and men differ, and to investigate the role of self-esteem and perceived parental attitudes in the determination of the fear of negative evaluation in women and men. To this end, 230 university students (125 of which were women) completed the Rosenberg Self-Esteem Scale, the Perceived Parental Attitudes Scale and the Brief Fear of Negative Evaluation Scale. The results suggest that perceived emotional warmth and rejection scores were different across genders. While women perceived more emotional warmth, men perceived higher rejective parental attitudes. Two different regression analyses were performed to determine the predictors of fear of negative evaluation in women and men. Low self-esteem accounted for $12 \%$ of the variance in fear of negative evaluation among women. Overprotective parental attitudes accounted for $20 \%$ of the variance in fear of negative evaluation among men. The findings indicate that gender role expectations should be taken into consideration in the investigation of those factors affecting the development of fear of negative evaluation and in the development of preventive interventions. In light of the findings of this study, it is believed that individual interventions which aim to improve self-esteem in women, and education programs which aim to encourage parents to develop positive parental attitudes could be effective as preventive interventions. Keywords: Perceived parental attitudes, fear of negative evaluation, self-esteem, social anxiety, gender

\section{EXTENDED ABSTRACT}

Recent studies in the field of social anxiety disorder (SAD) show that both individual and environmental factors play a role in the development of the disorder (Spence \& Rappee, 2016). In some studies, parenting style is considered a potential moderator in the relationship between social anxiety and temperament (Lewis-Morrarty et al., 2012; Rubin, Burgess, \& Hastings, 2002). It could be said that the parent's positive attitude towards the child can serve as a buffer against genetic predisposition, while his/her negative attitudes may increase the risk of developing social anxiety.

According to DSM-5, one of the key determinants of SAD is excessive worry about being evaluated or criticized by others (American Psychiatric Association, 2013). Although there are some studies suggesting that fear of negative evaluation (FNE) is related to body dysmorphic disorder, eating disorders and shyness (Gilbert \& Meyer, 2005a; Gilbert \& Meyer, 2005b; Menatti, Deboer, Weeks, \& Heimberg, 2015 ; Miller, 1995; Trompeter et al., 2018); Levinson and Rodebaugh (2012) stated that all these disorders may arise as a result of SAD.

In the literature, there are few studies pointing to the cultural factors and gender expectations in terms of the etiology of the FNE. The aim of this study was to examine the role of parental attitudes and self-esteem on the FNE. 


\section{Method}

\section{Participants}

The study sample consisted of 230 undergraduate students (125 of which were women) who participated voluntarily. Participants' ages ranged from 18 to 30 with a mean age of 21.1 $(S D=1.9)$ and $98.3 \%$ of the participants were single $(N=226)$.

\section{Measures}

In the study, the participants' age, gender, and marital status were found using a demographic questionnaire. The Perceived Parental Attitudes Scale (Arrindell et al., 1999; Dirik et al., 2015), the Rosenberg Self-Esteem Scale (Rosenberg, 1965; Çuhadaroğlu, 1986) and the Fear of Negative Evaluation Scale (Çetin, Doğan, \& Sapmaz, 2010; Leary, 1983) were used.

\section{Results}

The research was conducted in two stages. In the first step, perceived parental attitudes of men and women were compared. In the second step, the predictors of the FNE for women and men were tested by regression analysis.

The results indicated that there was a significant difference between the perceived emotional warmth $(t(228)=2.18, p<.05)$ and rejection $(t(228)=2.76, p<.05)$ of women and men. It was seen that women perceived more emotional warmth $(M=41.75, S D=7.95)$ than men $(M=39.42, S D=8.26)$. Furthermore, men perceived more rejective paternal and maternal attitudes $(M=20.14, S D=6.31)$ than women $(M=18.15, S D=4.58)$.

The results showed FNE and self-esteem $(r(228)=.30, p<.001)$; rejective attitudes $(r(228)$ $=.25, p<.001)$ and overprotective attitudes $(r(228)=.20, p<.05)$ were positively correlated. Multiple regression analysis showed that while self-esteem predicts FNE significantly for women $\left(R^{2}=.12, F(3,121)=5.69, p<.01\right)$; the only significant predictor was overprotective attitudes for men $\left(R^{2}=.17, F(3,101)=7.02, p<.001\right)$.

\section{Discussion}

In this study, it was observed that the variables which affect the development of FNE are different for women and men. While low self-esteem increased the risk of FNE fourfold in women, self-esteem did not appear to be a determinant of FNE in men. For men, overprotective parenting was the only significant predictor of FNE. According to traditional gender norms, men are expected to be independent and strong. Thus, autonomy supressing and over controlling parental attitudes would affect men negatively who were expected to be more independent. 
The effect of self-esteem on FNE for women can also be explained in the context of gender roles. In terms of gender roles, the self-concept of women and men differs according to the way they define themselves (Biolcati, 2017). While women define themselves in relation to others; men define themselves by focusing on how they are independent from others (Cross \& Madson, 1997; Marcic \& Grum, 2011).

This study was conducted with an adult population which required participants to recall childhood memories. It is believed that longitudinal studies on the adverse effects of parental attitudes would help more to explain the relationship between the development of self and FNE. This is the first study which highlights gender role differences in the etiology of FNE in the field. It is hoped that this study will lead to further studies addressing the effect of gender roles on the development of FNE.

The results of this study indicate that performing different interventions to prevent the development of the FNE in women and men would be more appropriate. It is believed that education programs which aim to develop positive parental attitudes among parents can be effective for men. Women on the other hand, might benefit more from individual interventions to improve self-esteem. 
Sosyal anksiyete bozukluğu alanında son yıllarda yapılan çalışmalar, söz konusu bozukluğun gelişiminde hem bireysel hem de çevresel faktörlerin rol oynadığını göstermektedir (Spence ve Rapee, 2016). Genetik yatkınlık ile çevresel faktörlerin etkileşimini ele alan bazı çalışmalarda ebeveynlik stili, sosyal anksiyete ile mizaç arasındaki ilişkide potansiyel bir biçimlendirici olarak görülmektedir (Lewis-Morrarty ve ark., 2012; Rubin, Burgess ve Hastings, 2002). Ebeveynin çocuğa yönelik pozitif tutumu, genetik yatkınlığa karşı bir tampon görevi görebilirken, negatif tutumu ise sosyal anksiyete geliştirme riskini arttırabilmektedir.

Sosyal anksiyete bozukluğu DSM-5'te diğerleri tarafindan olumsuz değerlendirilme, utandırılma, aşağılanma ya da reddedilme korkusu ve endişesi ile sosyal durum ya da etkileşimlerden uzak durma olarak tanımlanmaktadır (Diagnostic and Statistical Manual of Mental Disorders $5^{\text {th }}$ Edition; American Psychiatric Association, 2013). Sosyal anksiyeteye sahip insanlar, diğerleri tarafından olumsuz değerlendirilme olasılığından uzak durmak için sessiz kalma, göz kontağı kurmama gibi birçok davranışta bulunurlar ya da sosyal durumlara hiç girmemek için çabalarlar (Clark ve Wells, 1995; Wells ve ark., 1995). Tanımdan da anlaşılacağı üzere, diğerleri tarafindan olumsuz yönde değerlendirileceğinden ya da eleştirileceğinden endişe etmek sosyal anksiyetenin önemli belirleyicilerinden biridir. Sosyal anksiyetenin bilişsel modeline göre de sosyal anksiyete olumsuz değerlendirilme korkusuna (ODK'ye) bağlı olarak ortaya çıkmaktadır (Clark ve Wells, 1995; Rapee ve Heimberg, 1997). Heimberg, Brozovich ve Rapee (2010) sosyal anksiyetesi olan bireylerin ODK'ye sahip olduklarını ve bu nedenle dışarıdan gözle görünür olan titreme, terleme gibi belirtileri tehdit edici bularak bu belirtilere odaklandıklarını belirtmiştir. Yapılan çalışmalarda da ODK'si yüksek olan bireylerin, algılanan sosyal beceri düzeylerinin düşük olduğu, utangaçlık düzeylerinin de yüksek olduğu belirtilmektedir (Lundh ve Sperling, 2002; Miller, 1995; Stopa ve Clark, 1993). ODK'nin beden dismorfik bozukluğu, yeme bozuklukları ve utangaçlık ile ilişkili olduğuna işaret eden çalışmalar bulunsa da (Gilbert ve Meyer, 2005a; Gilbert ve Meyer, 2005b; Menatti, Deboer, Weeks ve Heimberg, 2015; Miller, 1995; Trompeter ve ark., 2018), Levinson ve Rodebaugh (2012) tüm bu bozuklukların sosyal anksiyetenin bir sonucu olarak ortaya çıkıyor olabileceğini belirtilmiştir. Bunu destekler şekilde Damercheli, Kakavand ve Jalali (2017) sosyal anksiyetenin beden dismorfik bozukluğu üzerinde direkt bir etkisi olduğunu ve bu etkiyi pozitif ve negatif değerlendirilme korkusu üzerinden yaptığını bulgulamıştır. Tüm bunlardan da anlaşılacağı üzere, ODK birçok ruh sağlığı sorunu ile arasında ilişki olduğu kanıtlanmış olan önemli bir bilişsel yapılanmadır. 
ODK'nin ortaya çıkışında kişinin kendine ve becerilerine yönelik değerlendirmelerinin etkili olduğu; kendisini sıkıcı olan, yeterince zeki ya da eğlenceli olmayan biri olarak değerlendiren kişilerde bu olumsuz değerlendirmeden kaynaklı bir ODK oluştuğu belirtilmektedir (Moscovitch, 2009). Bireyin kendini değerli görmesi ve kendine saygı duyması olarak tanımlanan benlik saygısı (Rosenberg, 1965) yüksek olduğunda kişinin hataları ya da eksikliklerine rağmen kendisine değer verdiği; düşük olduğunda ise kendi zayıflıklarına ilişkin algısının ağır bastığı görülmektedir (Rosenberg, 1979). $\mathrm{Bu}$ açıdan bakıldığında, düşük benlik saygısının da ODK'nin gelişmesinde bir risk faktörü olabileceği düşünülmektedir.

Alan yazında ODK'nin etiyolojisi açısından kültürel faktörler ve toplumsal cinsiyet rolü beklentilerine işaret eden çok az çalışma bulunduğu görülmektedir. Oysa bu faktörlerin etkisi hakkında bilgi sahibi olmak, daha kapsamlı önleyici müdahale programları geliştirilmesine katkıda bulunabilecektir. Bu çalışmada da ODK üzerinde algılanan ebeveyn tutumları ve benlik saygısının rolünün incelenmesi amaçlanmıştır.

\section{ODK, Benlik Sayıgısı ve Ebeveyn Tutumları}

Rohner (1975), sosyalizasyon kuramı olarak bilinen yaklaşımında çocuğun sosyal, bilişsel ve duygusal gelişiminde ebeveynin kabul edici ya da reddedici davranışlarının etkisi olduğunu ve bu etkinin yetişkin işlevselliğinde de devam ettiğini vurgulamıştır. Özellikle reddedici ebeveyne sahip çocuklar ebeveynin onayını almalarını daha başarılı, daha becerikli ya da daha uyumlu olmalarına bağladıkları için daha fazla hedef ve performans odaklı hale gelmektedirler. Ancak bu başarı - ebeveyn kabul/reddi ilişkisi yetişkinlikte işlevini yitirmektedir (Rohner, 1975). Performans odaklılık bu kez diğerlerinin gözünde yetersiz performans gösterme endişesine dönüşebilmektedir. Bununla birlikte, ebeveynlerin tutumları çocuğun 'benlik' kavramı gelişimini de önemli ölçüde etkilemektedir. Yapılan çalışmalar, ebeveynleri tarafından sıcaklık ve kabul görmeyen çocukların kendini değersiz görme, kendilerini olumsuz yönde eleştirme ve kendilerine olumsuz özellikler atfetme eğiliminin daha fazla olduğunu bildirmektedir (Berg ve Kelly, 1979; Gecas ve Schwalbe, 1986; Koydemir-Özden ve Demir, 2009). Ebeveynin reddedici oluşu gibi aşırı koruyucu oluşu da çocuğun benlik ve beceri gelişimini olumsuz etkilemektedir. Aşırı koruyucu tutumlar, çocuğun dünyanın tehlikeli bir yer olduğunu düşünmesine, kendine güvenini geliştirebileceği girişimlerden kaçınmasına ve bu nedenle becerilerini geliştirememesine sebep olmaktadır (Clarke, Cooper ve Creswell, 2013). Çeşitli kaygı sorunu olan kişilerle yapılan çalışmalar, bu kişilerin kaygı düzeyi 
daha düşük kişilere göre anne/babalarının daha koruyucu ve kontrolcü olduğuna işaret etmektedir (Dirik ve ark., 2015; Greco ve Morris, 2002; Parker, 1979).

Alan yazındaki bazı çalışmalar (Cohen, Mansoor, Gagin ve Lober, 2008; Furnham ve Cheng, 2000) düşük benlik saygısının reddedici ebeveyn tutumu ile ilişkili olduğunu göstermektedir. ODK'nin ölçüldüğü bir çalışmada ebeveyni tarafından kabul/onay görmeyen bireylerin benlik saygısı düzeylerinin daha düşük olduğu; katı ve kontrolcü ebeveyne sahip olan bireylerin ise ODK düzeylerinin arttığı görülmüştür (Koydemir-Özden ve Demir, 2009). Tüm bunlar göz önünde bulundurulduğunda ODK'nin etiyolojisinde hem ebeveyn tutumlarının hem de benlik saygısının rol oynadığı ancak bu değişkenlerin ODK ile ilişkisinin çok net olmadığg görülmektedir.

\section{ODK, Ebeveyn Tutumları ve Çocuğun Cinsiyeti}

İçinde yaşanılan kültür ebeveyn tutumlarını etkileyebilmektedir. Çocuk yetiştirme tarzları kültürden kültüre değişebilmektedir (Chen ve ark., 1998). Bununla birlikte kültüre özgü cinsiyet rolleri beklentisi de ebeveynlerin çocuklarına yaklaşımını değiştirebilmektedir. Toplumsal cinsiyet rolleri, her iki cinsiyet için de 'yapmalı' ve 'yapmamalı'ları tanımlar. Geleneksel cinsiyet rollerine göre, erkek çocukların bağımsız, agresif ve özgüvenli; kız çocukların ise duygusal ve hassas olması beklenmektedir (Stephens, 2009). Bu beklentiler ebeveynlerin davranış ve tutumlarının çocuklarının cinsiyetlerine göre değişmesine sebep olabilmektedir. Örneğin erkek çocuk ağladığında ya da üzüldüğünde ebeveynler bunu bir zayıflık göstergesi olarak algılayabilmektedir. Bu nedenle, kız çocukları ağladığında ya da sakinleştirilmesi gerektiğinde daha kabullenici davranan ebeveynler, erkek çocukları ağladığında ise daha az kabullenici davranışlar sergileyebilmektedir (Greenspan ve Shanker, 2004). Endendjik, Groeneveld, Bakermans-Kranenburg ve Mesman (2016) yaptıkları meta-analiz çalışmasında cinsiyet ve ebeveynlerin tutumları arasındaki ilişkiyi incelemiştir. Sonuçta ebeveynlerin erkek çocuklara, kız çocuklarından daha fazla kontrol edici tutumlarda bulundukları ve erkek çocuklara daha fazla katı fiziksel disiplin yöntemleri uygulandığı görülmüştür. Aynı çalışmada geleneksel cinsiyet rollerini benimsemiş ailelerin daha fazla cinsiyetçi ebeveynlik gösteriyor olabileceği de belirtilmiştir. Nitekim Çeçen (2008) Türkiye'de üniversite öğrencileri ile yürüttüğü çalışmada, kadın ve erkeklerin deneyimlediği ebeveyn tutumlarında farklılıklar olduğunu bulgulamıştır. Tüm bunlar göz önünde bulundurulduğunda, ebeveyn tutumlarının çocuğun cinsiyetine göre farklılık gösterebileceği ve bu farklılığın da ODK'nin gelişiminde kadın ve erkekler için farklı risk faktörlerine neden olabileceği düşünülmektedir. Buradan yola çıkarak kadın ve erkekler 
farklı ebeveyn tutumlarına maruz kalıyorlar ise deneyimlenen ebeveyn tutumlarının ODK üzerinde de farklı etkileri olabileceği düşünülmüştür. Şu ana kadar ODK üzerinde çevresel faktörler açısından kültür ve ebeveyn tutumları incelenmiş olsa da (Hofmann, Asnaani ve Hinton, 2010; Rapee ve Spence, 2004) ebeveyn tutumlarının çocuğun cinsiyeti ile etkileşimi sonucu ortaya çıkan tabloya ilişkin yeterince çalışma olmadığı görülmektedir. Bu nedenle iki aşamalı olarak gerçekleştirilen bu çalışmanın ilk aşamasında ebeveyn tutumlarının çocuğun cinsiyetine göre değiştiği varsayımının test edilmesi planlanmıştır. Araştırmanın ikinci aşamasında ise bu varsayımdan yola çıkılarak kadın ve erkeklerde ODK'nin bireysel (benlik saygısı) ve çevresel (ebeveyn tutumu) yordayıcılarının da farklılaşacağı öngörülmüştür. Bu nedenle kadın ve erkeklerde ayrı ayrı olacak şekilde ODK üzerinde algılanan ebeveyn tutumlarının ve benlik saygısının rolü incelenmiştir.

\section{YÖNTEM}

\section{Katılımcılar}

Araştırmanın örneklemini 2016 - 2017 öğretim yılında İstanbul'da bir vakıf üniversitesine kayıtlı lisans ve ön lisans programlarında okuyan öğrenciler oluşturmaktadır. Araştırmaya 125 'i (\%54.3) kadın olmak üzere toplam 230 üniversite öğrencisi katılmıştır. Katılımcıların yaşları 18 - 30 arasında değişmekte olup yaş ortalaması 21.1 'dir $(S S=$ 1.9). Katılımcıların 61'i (\%26.5) İktisadi ve İdari Bilimler Fakültesi, 54’ü (\%23.5) Fen Edebiyat Fakültesi, 51’i (\%22.2) Mühendislik ve Mimarlık Fakültesi, 46’s1 (\%20) Sağlık Meslek Yüksek Okulu (MYO), 6’s1 (\%2.6) Uygulamalı Bilimler MYO, 6’s1 (\%2.6) İletişim Fakültesi ve 5'i (\%2.2) Güzel Sanatlar Fakültesi’ne kayıtlıdır.

\section{Veri Toplama Araçları}

Araştırmada katılımcıların yaş, cinsiyet, medeni durum ve okudukları bölüme ilişkin bilgilerine demografik soru formu aracılığı ile ulaşılmıştır. Katılımcıların ebeveynlerinin tutumlarına ilişkin bilgi edinmek amacıyla katılımcıların kendisinden bilgi alındığı için Algılanan Ebeveyn Tutumları Ölçeği'nin (Arrindell ve ark., 1999; Dirik ve ark, 2015) çocuk kısa formu kullanılmıştır. Söz konusu tutumlar ile katılımcıların benlik saygıları ve diğerleri tarafından değerlendirilmeye ilişkin yaklaşımları ölçmek için Rosenberg Benlik Saygısı Ölçeği (Rosenberg,1965; Çuhadaroğlu, 1986) ve Olumsuz Değerlendirilme Korkusu Ölçeği (Çetin, Doğan ve Sapmaz, 2010; Leary, 1983) kullanılmıştır.

Kısaltılmış Algılanan Ebeveyn Tutumları Ölçeği- Çocuk Formu (KAET-Ç). Ölçek yetişkinlerin çocukluk döneminde deneyimledikleri ebeveyn tutumlarını duygusal 
sıcaklık, aşırı koruyuculuk ve reddedicilik olmak üzere üç alt boyutta ölçmek amacıyla geliştirilmiştir. Bu çalışmada ölçeğin Arrindell ve arkadaşları (1999) tarafından oluş̧urulan 23 maddelik kısa formu kullanılmıştır. Ölçek Türkçe'ye Dirik ve arkadaşları (2015) tarafindan uyarlanmış ve üniversite öğrencileri ile yürütülen bu çalışmada iç tutarlılık değerleri baba duygusal sıcaklık için .79, aşırı koruyuculuk için .73 ve reddedicilik için .71 bulunurken, anne tutumları için iç tutarlılık katsayıları ise duygusal sıcaklık, aşırı koruyuculuk ve reddedicilik için sırasıyla $.75, .72$, ve .64 olarak hesaplanmıştır. Analizlerde anne ve babalara ilişkin algılanan ebeveyn tutumlarının toplam puanları al1narak aşırı koruyucu ebeveyn tutumları, reddedici ebeveyn tutumları ve duygusal sıcaklık şeklinde oluşturulan değişkenler kullanılmıştır. Üniversite öğrencileri ile yürütülmüş olan bu çalışmada da iç tutarlık katsayıları duygusal sıcaklık, aşırı koruyuculuk ve reddedicilik için sırasıyla $.88, .84$ ve .84 olarak hesaplanmıştır.

Rosenberg Benlik Saygısı Ölçeği (R-BSÖ). Ölçek, bireylerin benlik saygısın ölçmek üzere geliştirilmiştir (Rosenberg, 1965). Ölçek, 63 madde ve 12 alt boyuttan oluşmaktadır. Bu çalışmada ölçeğin alt boyutlarından ilki olan Benlik Saygısı Ölçeği kullanılmıştır. Bu ölçek 5 olumlu 5 olumsuz madde olmak üzere toplam 10 maddeden oluşan bir ölçektir. Ölçekten alınan yüksek puanlar düşük benlik saygısına işaret etmektedir. R-BSÖ'nün Türkçe uyarlaması Çuhadaroğlu (1986) tarafindan ergenler üzerinde yapılmıştır ve benlik saygısı alt boyutu için iç tutarlılık katsayısı .75 olarak bulunmuştur. Ölçeğin geçerlik analizi için psikiyatrik görüşme yapılan öğrencilerin kendilerine ilişkin görüşleri yüksek, orta ve düşük olacak şekilde derecelendirilmiştir. Görüşme ve ölçekten alınan puanlar arasında geçerlilik katsayısı .71 olarak hesaplanmıştır. Korkmaz (1996), ölçeğin psikometrik özelliklerini test ettiği çalışmada yetişkinler için bu alt boyutun iç tutarlıl1k katsayısını .57 olarak bildirmiştir ve ölçeğin iki alt faktöre ayrıldığını gözlemlemiştir. Genç yetişkinler ile yürütülen bu çalışmada da benzer şekilde benlik sayıgısı alt ölçeğinin iç tutarlılık katsayısı .56 olarak hesaplanmıştır. Bu çalışmada ölçeğin psikometrik özelliklerinin gözden geçirilmesi hedeflenmediği için madde atımı yapılmamıştır.

Olumsuz Değerlendirilme Korkusu Ölçeği Kısa Formu (ODKÖ). ODKÖ, bireylerin çevresindekiler tarafından olumsuz değerlendirilmeye karşı toleransını ölçmek amaciyla geliştirilmiş 12 maddeden oluşan bir ölçektir. Ölçeğin üniversite öğrencilerinden oluşan örneklemde iç tutarlılık katsayısı .96 olarak bulunmuştur (Leary, 1983). Yine aynı çalışmada Leary, kısa formun, 30 maddelik özgün ölçek (Watson ve Friend, 1969) ile arasında .96 ilişki olduğunu bildirmiştir. Ölçeğin Türkçe uyarlama çalışması Çetin ve 
arkadaşları (2010) tarafından 325 üniversite öğrencisi ile gerçekleştirilmiş ve ölçeğin iç tutarlılık katsayısı .84 olarak hesaplanmıştır. Üniversite öğrencileri ile yapılan bu çalışmada da iç tutarlılık sayısı .84 olarak hesaplanmıştır.

\section{İşlem ve Veri Analizi}

Araştırma üniversiteye kayıtlı tüm öğrencilere ders içi ve ders dışı saatlerde duyurulduktan sonra araştırmaya katılmaya gönüllü olanlara soru formları ulaştırılmıştır. Kapalı zarf içerisinde ulaştırılan formlar yine kapalı zarf içerisinde toplanmıştır. Zarflar, tüm katılımcılardan veriler geldikten sonra açılmıştır. Böylece araştırmacının, hangi yanıtların hangi katılımcıya ait olduğunu bilmesinin önüne geçilmesi amaçlanmıştır.

Verilerin analizinde IBM SPSS 22 programı kullanılmıştır. Benlik saygısı, ODK ve algılanan ebeveyn tutumları arasındaki ilişki Pearson momentler çarpımı korelasyon katsayısı hesaplanarak incelenmiştir. Kadın ve erkeklerin deneyimlediği ebeveyn tutumlarının farklılaşıp farklılaşmadığını test etmek için algılanan ebeveyn tutumları ölçeğinden aldıkları puanlar bağımsız örneklemler için $t$ testi analizi ile karşılaştırılmıştır. Araştırma genç yetişkinler ile yürütüldüğü ve çocukluk dönemi anılarının geri çağrılmasında zamanın etkisinin olabileceği düşünülüp örneklem büyüklüğü de göz önünde bulundurularak, gruplar arası farkların yorumlanmasında $p$ değerinin yanı sıra etki büyüklüğü de (Hedges g katsayısı) hesaplanmıştır. Etki büyüklüğü değerleri yorumlanırken .29 ve altı düşük, $.30-.49$ arası orta, .50 ve üzeri yüksek düzey etki olarak alınmıştır (Cohen, 1988).

Hem kadın hem de erkeklerde ODK’yi yordayan değişkenleri tespit edebilmek amacıyla kadın ve erkeklerden elde edilen verilerde ayrı ayrı çoklu regresyon analizi kullanılmıştır. Regresyon analizde, aşırı koruyucu tutum, reddedici tutum, duygusal sıcaklık ve benlik saygısı değişkenleri yordayıcı değişkenler olarak test edilmiştir. Sonuç değişkeni ODK olmuştur.

\section{BULGULAR}

Kadın ve erkeklerin deneyimledikleri ebeveyn tutumları arasındaki farklılık incelendiğinde yalnızca duygusal sicaklık $(t(228)=2.18, p<.05)$ ve reddedici ebeveyn tutumu $(t(228)=-2.76, p<.05)$ puanlarının cinsiyete göre anlamlı farklılaştığı görülmüştür. Erkeklerin reddedici ebeveyn tutumu puan ortalamasının $($ Ort. $=20.14, S S=6.31)$ kadınların puan ortalamasından $($ Ort. $=18.15, S S=4.58)$ daha yüksek olduğu görülmüştür. Reddedici ebeveyn tutumu açısından gruplar arasındaki farkın etki büyüklüğü (Hedges $g$ ) 36 olarak hesaplanmıştır. Buna göre erkek olmak reddedici ebeveyn tutumuna sahip olmada 
orta düzey bir fark yaratmaktadır. Erkeklerin ebeveynlerinden algıladıkları duygusal s1caklık puan ortalamalarının ise (Ort. $=39.42, S S=8.26)$ kadınların puan ortalamalarından $($ Ort. $=41.75, S S=7.95)$ daha düşük olduğu görülmüştür. Duygusal sıcaklık açısından gruplar arasındaki farkın etki büyüklüğü (Hedges $g$ ) .29 olarak hesaplanmıştır. Buna göre erkek olmak ebeveynden duygusal sıcaklık görme açısından küçük bir fark yaratmaktadır. Aşırı koruyucu tutumlar açısından ise iki grup arasında bir fark yoktur $(t(228)<0.01$, $p>.05)$. Erkeklerin ODK puan ortalamalarının $($ Ort. $=29.01, S S=7.67)$ kadınların ortalamasından $($ Ort. $=27.20, S S=7.77)$ daha yüksek olduğu ancak bu farkın istatistiksel açıdan anlamlı olmadığı görülmüştür $(t(228)=-1.78, p>.05)$. Benlik saygısı puan ortalamaları karşılaştırıldığında kadınlar $($ Ort. $=1.01, S S=0.64)$ ve erkekler $(O r t .=1.29, S S$ $=2.17)$ arasında anlamlı bir fark olmadığ 1 sonucuna ulaşılmıştır $(t(228)=-1.35, p>.05)$. $\mathrm{Bu}$ bulgular, kadınlar ve erkekler arasında ODK düzeyi ve benlik saygısı düzeyi açısından bir fark bulunmadığını göstermektedir. Tüm örneklemde algılanan ebeveyn tutumları ile benlik saygısı ve ODK arasındaki ilişkiler Tablo 1'de gösterilmiştir.

Tabloda da görüldüğü üzere anne ve babanın reddedici tutumu arttıkça ODK artmakta ve benlik saygısı azalmaktadır. Benzer şekilde anne - babanın aşırı koruyu tutumu da

Tablo 1. Tüm Örneklemde ve Cinsiyete Göre Ebeveyn Tutumları, Benlik Saygısı ve Olumsuz Değerlendirilme Korkusu Arasındaki Korelasyon Katsayıları

\begin{tabular}{|c|c|c|c|c|c|}
\hline Tüm örneklem $(N=230)$ & 1 & 2 & 3 & 4 & 5 \\
\hline $\begin{array}{l}\text { 1.Olumsuz Değerlendirilme } \\
\text { Korkusu }\end{array}$ & - & & & & \\
\hline 2.Aşırı Koruyucu & $.20 *$ & - & & & \\
\hline 3.Reddedici & $.25^{* *}$ & $.35^{* *}$ & - & & \\
\hline 4.Duygusal Sicaklık & -.11 & -.01 & $-.36 * *$ & - & \\
\hline 5.Benlik Saygis1 & $.30^{* *}$ & $.20^{*}$ & $.25^{* *}$ & -05 & - \\
\hline $\operatorname{Kadın}(N=125)$ & 1 & 2 & 3 & 4 & 5 \\
\hline $\begin{array}{l}\text { 1.Olumsuz Değerlendirilme } \\
\text { Korkusu }\end{array}$ & - & & & & \\
\hline 2.Aşırı Koruyucu & .08 & - & & & \\
\hline 3.Reddedici & .10 & $.36^{* *}$ & - & & \\
\hline 4.Duygusal Sicaklık & -.04 & .01 & $-.48 * *$ & - & \\
\hline 5.Benlik Saygisı & $.35^{* *}$ & .12 & $.19^{*}$ & -.06 & - \\
\hline Erkek $(N=105)$ & 1 & 2 & 3 & 4 & 5 \\
\hline $\begin{array}{l}\text { 1.Olumsuz Değerlendirilme } \\
\text { Korkusu }\end{array}$ & - & & & & \\
\hline 2.Aşırı Koruyucu & $.39 * *$ & - & & & \\
\hline 3.Reddedici & $.26^{* *}$ & $.31^{* *}$ & - & & \\
\hline 4.Duygusal Sicaklık & -.19 & .00 & $-.21 *$ & - & \\
\hline 5.Benlik Saygisı & .04 & .02 & .07 & .03 & - \\
\hline
\end{tabular}


benlik saygısındaki azalma ve ODK'deki artışla ilişkili bulunmuştur. Duygusal sıcakl1ğın ODK ile negatif bir ilişkiye sahip olduğu ancak bu ilişkinin anlamlı olmadığı görülmüştür. Diğer yandan düşük benlik saygısı ile ODK arasında ise orta düzey pozitif ilişki olduğu görülmüştür $(r(228)=.30, p<.001)$.

Yapılan ilk analizde kadın ve erkeklerin deneyimlediği ebeveyn tutumlarının farkl1lık gösterdiği görülmüştü. Buradan yola çıkarak ODK üzerinde ebeveyn tutumları ve benlik saygısının rolünü inceleyebilmek amacıyla iki cinsiyet için ayrı ayrı regresyon analizi yapılmıştır. Kadın ve erkeklerde ODK'nin yordayıcıları açısından farklı paternlerin olup olmadığının netleştirilmesi amacıyla ODK ile anlamlı ilişki göstermeyen yordayıcılar da analize dahil edilmiştir. Her iki cinsiyet için yürütülen ve ebeveyn tutumları ile benlik saygının ODK üzerindeki etkisini sınayan çoklu regresyon analizlerinin sonuçları Tablo 2'de gösterilmiştir.

Tablo 2. Kadın ve Erkeklerde Olumsuz Değerlendirilme Korkusunun Yordanmasında Olumsuz Ebeveyn Tutumları ve Benlik Saygis1

\begin{tabular}{lccccc}
\hline & $\boldsymbol{R}^{2}$ & $\boldsymbol{B}$ & $\boldsymbol{\beta}$ & $\boldsymbol{t}$ & $\boldsymbol{p}$ \\
\hline Kadın & .12 & & & & \\
Düşük Benlik Saygısı & & 4.11 & 0.34 & 3.90 & $<.001$ \\
Reddedici & & 0.03 & 0.02 & 0.14 & .89 \\
Aşırı Koruyucu & 0.03 & 0.04 & 0.40 & .69 \\
Duygusal Sıcaklık & & -0.02 & -0.02 & -0.16 & .87 \\
Erkek & .20 & & & & \\
Düşük Benlik Saygısı & & 0.10 & 0.03 & 0.33 & .74 \\
Reddedici & & 0.14 & 0.12 & 1.21 & .23 \\
Aşırı Koruyucu & 0.34 & 0.35 & 3.72 & $<.001$ \\
Duygusal Sıcaklık & & -0.16 & -0.17 & -1.82 & .07
\end{tabular}

Sonuçlara göre kadınlarda ODK'yi benlik saygısı anlamlı şekilde yordarken $\left(R^{2}=\right.$ $.12, F(4,120)=4.24, p<.01)$; erkeklerde ODK'yi ebeveynlerin aşırı koruyucu tutumunun yordadığı görülmüştür $\left(R^{2}=.20, F(4,100)=6.21, p<.001\right)$.

\section{TARTIŞMA}

$\mathrm{Bu}$ çalışmada ebeveyn tutumları ile ODK ve benlik saygısı arasındaki ilişkinin kadın ve erkekler için ayrı ayrı incelenmesi amaçlanmıştır. Rohner'in (1975) ebeveyn kabul-red kuramına göre, her insan kendisine yakın olan ve kendisi için önemli olan anne babasından yakınlık ve sıcaklık görür. Bu sıcaklığın olmaması ise ebeveynin reddedici tutumu olarak adlandırılmaktadır. Rohner, anne babanın reddedici tutumu, düşük benlik 
saygısı, duygusal tutarsızlık, olumsuz dünya görüşü ve düşmanlık arasında bir ilişki olduğunu vurgulamıştır. Çocuğun karşılaştığı stresörler karşısında onun adına çözümler bulmayı içeren aşırı koruyucu ebeveynlik de çocuğun stresörler ile baş edebileceğine ilişkin inancının ve baş etme becerilerinin gelişmesini engellemektedir. Sosyal anksiyetede kişinin davranışlarının sonuçlarını dışsal faktörlere bağladığı görülür. Spokas ve Heimberg (2009) bu bilişsel yanlılığın gelişmesinde aşırı koruyucu ebeveyn tutumlarının etkili olduğunu belirtmiştir. Ebeveynin yaptığı kontrolün bir sonucu olarak çocuk gerekli sosyal becerileri edinememekte ve sosyal taleplerle karşı karşıya kaldığında kontrolünün olmadığını hissedebilmektedir. Bu dişsal kontrol, diğerleri tarafından olumsuz ya da olumlu değerlendirilme endişesi olarak karşımıza çıkabilmektedir. Yapılan araştırmalar da bu görüşü destekleyecek şekilde, reddedici ve aşırı koruyucu ebeveyn tutumlarının sosyal anksiyete ile ilişkili olduğuna işaret etmektedir (Lieb ve ark., 2000; Lindhout ve ark., 2006). Yapılan bu çalışmada da sosyal anksiyetenin bilişsel öğelerinden olan ODK'nin sırasıyla benlik saygısı, ebeveynin reddedici tutumu ve aşırı koruyuculuğu ile ilişkili olduğu görülmüştür.

Yapılan çalışmada, kadın ve erkeklerin deneyimlediği ebeveyn tutumlarının beklendiği gibi farklılaştığı görülmüştür. Katılımcıların cinsiyetlerine göre algıladıkları ebeveyn tutumları incelendiğinde, erkeklerin ebeveynlerinden reddedici tutum deneyimleme düzeyleri daha yüksek iken duygusal sıcaklık deneyimleme düzeylerinin daha düşük olduğu görülmüştür. Akgül ve Dirik (2018) de ergenler ile yaptığı çalışmada benzer şekilde kadınların ebeveynlerinden erkeklere göre daha fazla duygusal sıcaklık algıladıklarını bulgulamıştır. Aynı araştırmada kadınların erkeklerden daha yükssek düzeyde aşırı koruyuculuk deneyimledikleri görülmüştür. Yapılan bu çalışmada ise aşırı koruyuculuk açısından iki cinsiyet arasında bir fark bulunmamıştır. Araştırma örneklemlerinin farklı yaş gruplarından oluşması; bu çalışmada 18 yaş üzeri genç yetişkinler ile çalışılmış olması bu farka neden olmuş olabilir.

Kadın ve erkeklerin farklı ebeveyn tutumları algılamalarını toplumsal cinsiyet rolleri bağlamında açıklamak mümkündür. Cinsiyet rolleri göz önünde bulundurulduğunda, ebeveynlerin çocuklarının biyolojik cinsiyetlerine göre farklı yaklaşımlar gösterdikleri bilinmektedir (Brody, 1999). Brody (2000), bu farklılığın özellikle duyguların ifadesi alanında gözlendiğini; erkeklerin üzüntü, utanç, depresyon, korku gibi duyguları ifade etmesinin kabul olmadığı sadece öfke ve agresyon ifadesinin kabul gördügüünü söylemiştir. Bu açıdan bakıldığında, erkeklerin çocukken sergilediği duygu ve davranışların 
birçoğunun 'erkek' çocuk oldukları için kabul görmediğini, bu nedenle de anne ve babalarını daha fazla reddedici algıladıklarını söyleyebiliriz. Bu durum karşısında, erkekler ebeveynlerinden kabul görebilmek için maskülen rol beklentilerini yerine getirme çabasına odaklanıyor olabilir. Bu beklenti de maskülen rolü layıkıyla yerine getiremediğine ilişkin bir endişeye ve bu endişeyle ilişkili olarak ODK'ye yol açıyor olabilir. Bruch’ın (2007) yaptığı çalışma da bu kuramı destekler niteliktedir. Bruch (2007), erkeklerin dayanıklı maskülen rol beklentilerinin sosyal anksiyete üzerinde biçimlendirici etkisi olduğunu tespit etmiştir. Diğer yandan anne ve babalar, erkek çocuklarının kız çocukları kadar duygusal sıcaklığa ihtiyacı olmadığını düşünüyor; bu nedenle de onlara daha soğuk ve mesafeli duruyor olabilirler. Bu da erkeklerin hem anne hem de babadan daha fazla reddedilmişlik algılamasına sebep oluyor olabilir. Bununla birlikte kadınların duygularının ebeveynleri tarafindan daha fazla kabul edilmesi ebeveynlerinden algıladıkları duygusal sıcaklık düzeyini arttırıyor olabilir.

Yapılan çalışmada ebeveyn tutumlarının cinsiyete göre farklılaşması, ODK yordayıcılarının her iki cinsiyet için farklılaşması sonucunu doğurmuştur. Buna göre düşük benlik saygısı, kadınlarda ODK' deki varyansın \%12'sini açıklarken, erkeklerde ODK'yi belirleyen bir değişken olmadığı görülmüştür. Bunun yerine erkeklerde aşırı koruyucu tutumun ODK' yi arttırdığı görülmüştür. Toplumsal cinsiyet rolleri ile ilişkili olarak kadın ve erkeklerin benlik anlayışlarını neye göre tanımladıkları farklılaşmaktadır (Biolcati, 2017). Buna göre erkekler bireysel hedeflere odaklanmak, bireysel başarı ve güçlerini sergilemek, böylece diğerlerinden ne kadar farklı oldukları üzerinden kendilerini tanımlamaktadır. Kadınlar ise diğerleri ile ilişkileri içerisinde kendilerini tanımlamaktadır (Cross ve Madson, 1997; Marcic ve Grum, 2011). Bu açıdan ele alındığında, erkeklerin daha bağımsız olmayı arzularken özerkliği baskılayan kontrolcü ve aşırı koruyucu tutumlara maruz kalmaları olumsuz değerlendirileceklerine ilişkin endişe duymalarına neden oluyor olabilir. Yine toplumsal cinsiyet bağlamında kadınlarda benlik saygısının ODK'yi belirliyor oluşu da oldukça anlamlıdır. Kadınlar, erkeklere göre diğerlerinin değerlendirmesine karşı daha hassastır çünkü benlik tanımlarında diğerleri ile ilişkileri önemli bir yer tutmaktadır (Biolcati, 2017). Higgins'e (1987) göre öz değerlendirmesi ile diğerlerinin kendileri hakkında düşündükleri arasında bir farklılık olduğunu düşünen kadınlarda olumsuz değerlendirilme ve cezalandırılma korkusu da artmaktadır. Tüm bunların yanında benlik saygısı bilgisinin öz bildirim ölçeği yolu ile elde edilmiş oldu$\breve{g u}$, bu nedenle elde edilen sonuçların yüksek kaygılı bireylerin kendilerine ilişkin olum- 
suz değerlendirmelerine ve benlik sunumu kaygılarının yoğunluğuna işaret ediyor olabileceği de (De Jong, 2002) göz önünde bulundurulmalıdır.

Benlik saygısı ile ODK arasında kadınlarda doğrudan bir ilişki bulunurken, erkeklerde bu ilişkinin zayıf olması erkeklerin algıladığı kontrolcü ve reddedici tutumun benlik gelişiminde nasıl bir etkisi olduğu sorusunu akla getirmektir. Bu nedenle erkeklerde ebeveyn tutumları ile ODK arasındaki ilişkide hangi değişkenlerin rol oynadığının daha derinlemesine araştırılması gerektiği düşünülmüştür. Tüm bunlar göz önünde bulundurulduğunda, toplumsal cinsiyet rollerinin, ODK'yi belirleyen faktörlerin cinsiyete göre farklılaşmasında bir etkisinin olabileceğine işaret etmektedir. Bu bağlamda, sosyal psikiyatri alanında daha fazla çalışmaya ihtiyaç olduğu düşünülmektedir.

Olumsuz değerlendirilme korkusuna sosyal psikiyatrik bir bakış açısı ile yaklaşan bu araştırmanın metadolojik birtakım sınırlılıkları da bulunmaktadır. Araştırma örneklemi 18 yaş ve üzeri bir gruptan oluşmaktadır ve bu yaştaki bireylerin erken dönem çocukluk anılarını eksiksiz olarak hatırlaması oldukça zordur. Bu durum, ebeveyn tutumları ile ODK ve benlik saygısı arasındaki ilişkinin olduğundan daha düşük düzeyde çıkmasına sebep olmuş olabilir. Katılımcıların benlik saygısını ölçmek için kullanılan ölçeğin psikometrik özelliklerinin bu örneklemde yeterli olmadığı, benzer bir çalışmanın daha iyi çalışan bir ölçüm aracı ile tekrarlanmasının yerinde olacağı düşünülmüştür. Ayrıca ebeveyn tutumlarının olumsuz etkileri ile ilgili boylamsal çalışmalar yapılmasının, ODK ve benlik gelişimi ile arasındaki ilişkinin açıklanmasına yardımcı olacağı düşünülmektedir.

Endendjik ve arkadaşları (2016) 1990'lara kadar ebeveynlerin erkek çocukların otonomisini destekleyen tutumlar sergilediğini ancak 90'lardan sonra kız çocuklara karş1 daha fazla destekleyici olduklarını, diğer yandan erkeklere yönelik kontrolcü tutumların da arttığını belirtmiştir. Bu çalışmada ise kadın ve erkeklerin otonomiyi baskılayan aşırı koruyucu tutumlara maruz kalması arasında fark olmadığı görülmüştür. Türkiye'de yapılan bu çalışmanın bulgularının, çoğunluğu Batı'da yapılmış araştırmaların bulgularından farklılaşması sonucunda Türkiye'de cinsiyet rolleri ve ebeveyn tutumları arasındaki ilişkiyi zamansal açıdan inceleyen çalışmaların yapılmasının yerinde olacağı düşünülmüştür. Böylelikle ebeveyn tutumlarındaki değişimlerin ve bunun çocuklar üzerindeki etkisinin cinsiyete bağlı olarak gözlenmesi mümkün olabilir. Kadın ve erkeklerde ODK'nin belirleyicilerinin farklılaşıyor olması, kadınlarda ebeveyn tutumlarının etkisinin görülmemesi ise araştırmadaki dikkat çekici bir diğer noktadır. Literatürde ODK'nin belirleyi- 
cilerini cinsiyetler açısından ele alan bir çalışmaya rastlanmamıştır ancak benlik saygısı açısından ailenin etkisinin araştırıldığı bazı çalışmalar bulunmaktadır. Örneğin; Demo, Small ve Savin-Williams (1987) erkeklerin benlik saygısının kadınlara göre aile ile daha fazla ilişkili olduğunu belirtmiştir. Quatman ve Watson (2001) ise aile yaşamının benlik saygısı üzerinde hem kadın hem de erkekler için güçlü bir etkisi olduğunu bulgulamıştır. Literatürdeki tutarsız bulgular, kadın ve erkeklerin hem bilişsel ve sosyal gelişimlerinin hem de benlik gelişimlerinin ebeveyn tutumlarından nasıl etkilendiğini açıklamaya yönelik daha fazla araştırma yapılması gerektiğini göstermektedir. Bu çalışmanın sonuçları, sosyal kaygının öncülü olan ODK'nin gelişmesini önlemede kadın ve erkekler için farklı müdahaleler geliştirilmesinin yerinde olabileceğine işaret etmektedir. Buna göre kadınlarda benlik saygısını geliştirmeye yönelik bireysel müdahaleler etkili olabilecekken, erkeklerde ebeveynlerini hedef alan olumlu ebeveyn tutumlarını geliştirmeye yönelik eğitim programlarının etkili olabileceği düşünülmektedir. Bu araştırma, sosyal kaygının önemli belirleyicilerinden biri olan ODK'nin yordayıcılarını cinsiyetler açısından ele alan bilinen ilk çalışmadır ve bu çalışmanın, sosyal kaygının gelişimi, ortaya çıkışı ve bildiriminde çevresel değişkenleri ele alan araştırmalara yol göstereceği umulmaktadır.

Finansal Destek: Yazar bu çalıșma için finansal destek almamıștır.

\section{Kaynakça}

Akgül, G. ve Dirik, G. (2018). Perceived parental attitudes and hopelessness in predicting social anxiety symptoms of Turkish male and female adolescents. International Journal of Arts and Social Science, 1(3), 37-45.

American Psychiatric Association (2013). Diagnostic and statistical manual of mental disorders. (5th ed.). Washington, DC: American Psychiatric Publishing.

Arrindell, W. A., Sanavio, E., Aguilar, G., Sica, C., Hatzichristou, C., Eisemann, M., ... ve van der Ende, J. (1999). The development of a short form of the EMBU: its appraisal with students in Greece, Guatemala, Hungary, and Italy. Personality and Individual Differences, 27, 613-28.

Berg, B. ve Kelly, R. (1979). The measured self-esteem of children from broken, rejected, and accepted families. Journal of Divorce, 2(4), 363-369.

Biolcati, R. (2017). The role of self-esteem and fear of negative evaluation in compulsive buying. Frontiers in Psychiatry, 74, 1-8.

Brody, L. R. (1999). Gender, emotion and the family. Cambridge, MA: Harvard University Press.

Brody, L. R. (2000). The socialization of gender differences in emotional expression: Display rules, infant temperament, and differentiation. Gender and emotion: Social psychological perspectives (ss. 24-47). Cambridge: Gambridge University Press.

Bruch, M. A. (2007). Cognitive bias in men's processing of negative social information: The role of social anxiety, toughness as a masculine role norm, and their interaction. Cognitive Therapy and Research, 31(3), 273-289. 
Chen, X., Hastings, P. D., Rubin, K. H., Chen, H., Cen, G. ve Stewart, S. L. (1998). Childrearing attitudes and behavioral inhibition in Chinese and Canadian toddlers: A cross-cultural study. Developmental Psychology, 34(4), 677-686.

Clarke, K., Cooper, P. ve Creswell, C. (2013). The Parental Overprotection Scale: Associations with child and parental anxiety. Journal of Affective Disorders, 151(2), 618-624.

Clark, D. M. ve Wells, A. (1995). A cognitive model of social phobia. R. G. Heimberg, M. R. Liebowitz, D. A. Hope ve F. R. Schneier (Ed.), Social phobia: Diagnosis, assessment, and treatment içinde (ss. 69-93). New York: Guilford Press.

Cohen, J. (1988). Statistical power analysis for the behavioral sciences (2. bask1). Hillsdale, NJ: Erlbaum.

Cohen, M., Mansoor, D., Gagin, R. ve Lorber, A. (2008). Perceived parenting style, self-esteem and psychological distress in adolescents with heart disease. Psychology, Health and Medicine, 13(4), 381-388.

Cross, S. E. ve Madson, L. (1997). Models of the self: Self-construals and gender. Psychological Bulletin, 122(1), 5-37.

Çeçen, A. R. (2008). Öğrencilerin cinsiyetlerine ve ana-baba tutum algılarına göre yalnızlık ve sosyal destek düzeylerinin incelenmesi. Türk Eğitim Bilimleri Dergisi, 6(3), 415-431.

Çetin, B., Doğan, T. ve Sapmaz, F. (2010). Olumsuz Değerlendirilme Korkusu Ölçeği Kısa Formu'nun Türkçe uyarlaması: Geçerlik ve güvenirlik çalışması. Ĕ̈itim ve Bilim, 35, 205-216.

Çuhadaroğlu, F. (1986). Adolesanlarda benlik saygısı (Yayınlanmamış tıpta uzmanlık tezi). Hacettepe Üniversitesi, Ankara.

Damercheli, N., Kakavand, A. R. ve Jalali, M. R. (2017). Proposing a model for analysing relationship between social anxiety and body dysmorphic disorder: Mediating role of fear of positive and negative evaluation. International Journal of Medical Research and Health Sciences, 6(2), 91-103.

De Jong, P. J. (2002). Implicit self-esteem and social anxiety: Differential self-favouring effects in high and low anxious individuals. Behaviour Research and Therapy, 40, 501-508.

Demo, D. H., Small, S. A. ve Savin-Williams, R. C. (1987). Family relations and the self-esteem of adolescents and their parents. Journal of Marriage and the Family, 49, 705-715.

Dirik, G., Yorulmaz, O. ve Karancı, A. N. (2015). Çocukluk dönemi ebeveyn tutumlarının değerlendirilmesi: Kısaltılmış Algılanan Ebeveyn Tutumları-Çocuk Formu. Türk Psikiyatri Dergisi, 26, 123-130.

Endendjik, J. J., Groeneveld, M. G., Bakermans-Kranenburg, M. J. ve Mesman, J. (2016). Genderdifferentiated parenting revisited: Meta-analysis reveals very few differences in parental control of boys and girls. PLoS One, 11(7), e 0159193.

Furnham, A. ve Cheng, H. (2000). Perceived parental behaviour, self-esteem and happiness. Social Psychiatry and Psychiatric Epidemiology, 35(10), 463-470.

Gecas, V. ve Schwalbe, M. (1986). Parental behavior and adolescent self-esteem. Journal of Marriage and Family, 48(1), 37-46.

Gilbert, N. ve Meyer, C. (2005a). Fear of negative evaluation and eating attitudes: A replication and extension study. International Journal of Eating Disorders, 37(4), 360-363.

Gilbert, N. ve Meyer, C. (2005b). Fear of negative evaluation and the development of eating psychopathology: A longitudinal study among nonclinical women. International Journal of Eating Disorders, 37(4), 307-312.

Greenspan, S. I. ve Shanker, S. G. (2004). The first idea: How symbols, language, and intelligence evolved from our primate ancestors to modern humans. Cambridge: Da Capo Press. 
Greco, L. A. ve Morris, T. L. (2002). Paternal child-rearing style and child social anxiety: Investigation of child perceptions and actual father behavior. Journal of Psychopathology and Behavioral Assessment, 24(4), 259-267.

Heimberg, R. G., Brozovich, F. A. ve Rapee, R. M. (2010). A cognitive-behavioral model of social anxiety disorder: Update and extension. Social anxiety: Clinical, developmental, and social perspectives içinde (ss. 395-422). Cambridge: Academic Press.

Higgins, E. T. (1987). Self-discrepancy: A theory relating self and affect. Psychological Review, 94, 319-340.

Hofmann, S. G., Asnaani, A. ve Hinton, D. E. (2010). Cultural aspects in social anxiety and social anxiety disorder. Depression and Anxiety, 27(12), 1117-1127.

Korkmaz, M. (1996). Yetişkin örneklem için bir benlik saygısı ölçeğinin güvenirlik ve geçerlik çalışması (Yayınlanmamış yükssek lisans tezi). Ege Üniversitesi, İzmir.

Koydemir-Özden, S. ve Demir, A. (2009). The relationship between perceived parental attitudes and shyness among Turkish youth: Fear of negative evaluation and self-esteem as mediators. Current Psychology, 28(3), 169-180.

Leary, M. R. (1983). A brief version of the Fear of Negative Evaluation Scale. Personality and Social Psychology Bulletin, 9, 371-376.

Levinson, C. A. ve Rodebaugh, T. L. (2012). Social anxiety and eating disorder comorbidity: The role of negative social evaluation fears. Eating Behaviors, 13(1), 27-35.

Lewis-Morrarty, E., Degnan, K. A., Chronis-Tuscano, A., Rubin, K. H., Cheah, C. S. L., Pine, D. S., ... ve Fox, N. A. (2012). Maternal over-control moderates the association between early childhood behavioral inhibition and adolescent social anxiety symptoms. Journal of Abnormal Child Psychology, 40(8), 1363-1373.

Lieb, R., Wittchen, H. U., Hofler, M., Fuetsch, M., Martina, S., Murray, B. ve Merikangas, K. R. (2000). Parental psychopathology, parenting styles, and the risk of social phobia in offspring: A prospective-longitudinal community study. Archives of General Psychiatry, 57, 859-866.

Lindhout, I., Markus, M., Hoogendijk, T., Borst, S., Maingay, R., Spinhoven, P., ... ve Boer, F. (2006). Child rearing style of anxiety-disordered parents. Child Psychiatry and Human Development, 37(1), 89-102.

Lundh, L. ve Sperling, M. (2002). Social anxiety and the post-event processing of socially distressing events. Cognitive Behaviour Therapy, 31, 129-134.

Marcic, R. ve Grum, D. K. (2011). Gender differences in self-concept and self-esteem components. Studia Psychologica, 53(4), 373-384.

Menatti, A. R., DeBoer, L. B. H., Weeks, J. W. ve Heimberg, R. G. (2015). Social anxiety and associations with eating psychopathology: Mediating effects of fears of evaluation. Body Image, 14, 20-28.

Miller, R. S. (1995). On the nature of embarrassability: Shyness, social evaluation, and social skill. Journal of Personality, 63, 315-339.

Moscovitch, D. A. (2009). What is the core fear in social phobia? A new model to facilitate individualized case conceptualization and treatment. Cognitive and Behavioral Practice, 16(2), 123-134.

Quatman, T. ve Watson, C. M. (2001) Gender differences in adolescent self-esteem: An exploration of domains. The Journal of Genetic Psychology, 162(1), 93-117.

Parker, G. (1979). Reported parental characteristics of agoraphobics and social phobics. The British Journal of Psychiatry, 135(6), 555-560.

Rapee, R. M. ve Heimberg, R. G. (1997). A cognitive-behavioral model of anxiety in social phobia. Behaviour Research and Therapy, 35, 741-756. 
Rapee, R. M. ve Spence, S. H. (2004). The etiology of social phobia: Empirical evidence and an initial model. Clinical Psychology Review, 24(7), 737-767.

Rubin, K. H., Burgess, K. B. ve Hastings, P. D. (2002). Stability and social-behavioral consequences of toddlers' inhibited temperament and parenting behaviors. Child Development, 73(2), 483-495.

Rohner, R. P. (1975). They love me, they love me not: A worldwide study of the effects of parental acceptance and rejection. New Haven: Human Relations Area Files Press.

Rosenberg, M. (1965). Society and the adolescent self image. Princeton, NJ: Princton University Press. Rosenberg, M. (1979). Conceiving the self. New York: Basic Books.

Spokas, M. ve Heimberg, R. G. (2009). Overprotective parenting, social anxiety, and external locus of control: Cross-sectional and longitudinal relationships. Cognitive Therapy And Research, 33(6), 543.

Spence, S. H. ve Rapee, R. M. (2016). The etiology of social anxiety disorder: An evidence-based model. Behaviour Research and Therapy, 86, 50-67.

Stephens, M. A. (2009). Gender differences in parenting styles and effects on the parent-child relationship (Yayınlanmamış bitirme tezi). Texas State University, Texas.

Stopa, L. ve Clark, D. M. (1993). Cognitive processes in social phobia. Behaviour Research and Therapy, 31, 255-267.

Trompeter, N., Bussey, K., Hay, P., Mond, J., Murray, S. B., Lonergan, A., ... ve Mitchison, D. (2018). Fear of negative evaluation and weight/shape concerns among adolescents: The moderating effects of gender and weight status. Journal of Youth and Adolescence, 47(7), 1398-1408.

Watson, D. ve Friend, R. (1969). Measurement of social-evaluative anxiety. Journal of Consulting and Clinical Psychology, 33(4), 448-457.

Wells, A., Clark, D. M., Salkovskis, P., Ludgate, J., Hackmann, A. ve Gelder, M. (1995). Social phobia: The role of insituation safety behaviors in maintaining anxiety and negative beliefs. Behavior Therapy, 26, 153-161. 
